\title{
Can we ever have a 'right to die'? A reflective consideration of assisted suicide in Ireland
}

\author{
James Keogh \\ Department of Sociology \& Philosophy, UCC
}

\author{
So the choice I have made \\ May seem strange to you \\ But, who asked you anyway? \\ It's my life to wreck, \\ My own way. \\ - Morrissey 'Alma Matters'
}

\section{Introduction}

There is perhaps no greater moral or ethical quandary than reasoning to prematurely end a life; assisted suicide certainly resides within that contested bracket. Helping another to die is probably the most intensely personal test of individual conscience known to mankind. Most of us are shocked and revolted by murder, suicide and genocide, but when someone we know and love cries out, with justification, for help to die, how are we to respond? If we help to accelerate death in these circumstances, are we being ruthless or humane? There appears to be more questions than definitive answers surrounding one's 'right-todie' emphasising the complexity of the issue at hand.

Numerous social and political commentators stress a need for 'serious debate' on this topic. But what level of discussion and interaction constitutes serious debate and where in the public arena is this to take place? To date, formal discussion on this issue has been severely limited. The topic of assisted suicide has however exploded to the forefront of Irish society in recent times. The occurrence of two high-profile legal cases in the past three years has sparked increased interest in this issue. Although these cases are tragic in nature because of their implicit relationship to circumstances pertaining to death, they have effectually forced society to give this subject the long overdue attention it deserves. In doing so, these cases have provided a voice for some of the most vulnerable in society - those who are suffering at the end of their days. 


\section{Legal contestations}

In 2013 Marie Fleming, who suffered from Multiple Sclerosis (MS), took her case for the right-to-die through the judicial process. Her attempt in seeking that right failed in the High Court and that decision was subsequently upheld in the Supreme Court. Upon delivering his verdict, High Court President Mr Justice Nicholas Kearns described Ms Fleming as a 'humbling and inspiring' person and one of the most remarkable witnesses to come before the courts, while describing her experience as 'harrowing'. Although there were heartfelt and emphatic signs of sympathy shown towards Ms Fleming, the court fell short of granting her request to die at a time of her choosing. It had been hoped that Ms Fleming would secure an order requiring the Director of Public Prosecutions (DPP) to clarify its policy on the factors which would be considered when exercising its discretion to prosecute for the crime of assisted suicide. This approach would see assisted suicide remain a criminal offence, but members of the public would have a better understanding of the level of risk they would be exposed to should they assist another to commit suicide. The court refused to release a publication on such guidance.

In April of this year, the harsh reality of those 'levels of risk' became all too real when Gail O'Rorke was the first person in the State to be prosecuted under Section 2 of the Criminal Law Act, 1993. She was charged with aiding, abetting, counselling or procuring the suicide of Bernadette Forde in 2011 which carries a sentence of up to fourteen years in jail. O'Rorke denied that she attempted to aid and abet the suicide of Ms Forde by means of arranging travel to Zurich, Switzerland for such purpose. Furthermore, O'Rorke refuted that she procured the suicide of Ms Forde by means of making funeral arrangements for Ms Forde in advance of her death. Authorities were alerted after a travel agent became aware both parties were travelling to Zurich to visit Dignitas (euthanasia clinic). Any assistance, including travel aid of any description, under Irish law, is considered assisting a suicide. Having becoming concerned about implicating her friend in aiding her death, Ms Forde sourced barbiturates online from Mexico and administered a lethal dose at home alone. Gail O'Rorke was acquitted on all charges after evidence was heard via a Dictaphone recording from Forde herself exonerating the accused.

There are some poignant lessons to be gained from these trials which society must acknowledge. Their impassioned content profoundly exposes the plight of those who are forced to suffer against their wishes; the brevity of time between the two cases highlights the rapid growing demand for legislative change on this issue. Those in power cannot afford to sit on their hands and continue to ignore this topic. Interestingly, a recent Irish Times Ipsos/MRBI poll found fifty-four per cent agree there are circumstances where they would be willing to help a family member die. Dissecting those findings, over half of those surveyed would take the law into their own hands and risk fourteen years imprisonment to assuage the suffering of a loved one. What does all of the above suggest? What appears to be occurring is a reflective recalibration of public attitudes around assisted suicide in 
Ireland. Evidently existing legislation no longer reflects public opinion on this matter. Therefore, is this democratically acceptable? The foremost aim of my research is to investigate the changing circumstances surrounding the fight for a right to choose to die and ultimately consider "can we ever have a "right to die"" in Ireland?

\section{Research aims and methodology}

The right-to-die debate comprises of an amalgamation of competing claims. Its considerations include philosophical, ethical, moral, theological, and perceived 'rights' based contestations in the fight for recognition. The various elements of its rights' entitlement narrative reflect the input provided by legal, political, and social arenas, including the media. In particular this input pertains to the question of the individual's right to recognition (e.g., of autonomy, experiences of suffering, loss of dignity), equal opportunity, political representation and a voice before the law. Polemic interpretations of (in)justice highlight some fundamental issues at the core of this debate. An aim of my research is to analyse how political and legal actors both inside and outside of the dominant circuit of institutional power challenge traditional interpretations of justice on this issue. These actors not only call for a reform of the law in relation to the right-to-die, they also disclose new dimensions of justice that frequently transgress the established grammar of 'normal justice' (established legal-political and social interpretations of justice) exploring new conceptions of rights' entitlements in relation to this issue.

To gather these conflicting interpretations, I will employ a qualitative interviewing method. This will entail carrying out semi-structured interviews with those at the heart of this debate, consisting of influential legal and political actors as well as individuals directly seeking the right to die or those acting on their behalf. These interviews have yet to be carried out. I am currently at the stage of strategically identifying potential participants who will best reflect the associated contestations of the subject matter as ascertained from a preliminary review of germane literature. The advantage of a qualitative interview approach for my study lies in its facilitation of in-depth analysis of participant's subjective experiences, much of which will undoubtedly be highly emotive, sensitive, and outside the realm of rigid definable variables. This research method enables the cultivation and maintenance of sensitivity to the social, cultural, and the historical caveats of this debate, impossible to consider with quantitative methods.

Using this data, my analysis will follow the theoretical recommendations of Axel Honneth, who calls for a negative reconstruction of society. This stipulation permits the definition of justice to be 'provided by the criteria of the experiences of injustice rather than by a reconstruction of our intuitions of justice'.

Once my empirical data is assembled, I will juxtapose those interviewees' viewpoints to definitively identify the fundamental contestations within this debate. Each participant's justificatory reasoning will reveal both the 'for' and 'against' rationalisations ascribed to 
the right-to-die argument. The legitimacy of each competing claim for rights entitlement will be philosophically mediated to test whether it matches contemporary society's expectations and the will of the majority of its people. Honneth's supposition of reconstructing a fairer society can only be met once injustice claims are brought together in a coherent framework for deliberation. A framing technique thus enables the researcher to assign 'value' to each competing claim. From here, a hierarchal ordering of these opposing assertions, in accordance to their resonance with society, will conclusively establish whether or not a call to alter existing legislation on the right-to-die is justified. To draw this conclusion I will reflect my qualitative findings against the principles of the most prolific social theorists and philosophers concerned with justice, human rights, theological and political philosophy. By interweaving participant's accounts of experienced (in)justice, political (mis)representation, media attention (or lack thereof), with the work of John Rawls, Amartya Sen, Axel Honneth, Rainer Forst and Nancy Fraser, will ensure the production of a comprehensive study producing the most fruitful empirical research of the right-to-die on these shores. That is the crux of my research.

\section{Potential impact of this study}

While researching for my Master's thesis in 2013, I discovered how underdeveloped this topic is in terms of sociological input. The vast majority of existing material relating to this subject in Ireland emanates purely from a legal viewpoint. A major drawback associated with this finding, which elevates the need for my research, is that legal studies themselves do not explore nor present the ever-changing expectations of society, which is a significant catalyst for policy reform. With the debate on the right-to-die still in its infancy here in Ireland, research investigating communication between and across distinct value perspectives as well as life experiences of the different actors involved in the Irish context is virtually non-existent. My study will acknowledge these considerations, therefore, making a new contribution to knowledge in this field. A sociological and philosophical perspective is needed to account for the numerous crucial dimensions of this debate including: how ideas of social justice come to be articulated by different actors in society, how moral-ethical learning is understood, how communication across differing value positions is facilitated by the media, how different actors interpret the importance of adapting to a changing Irish society, and whether or not the existing political model, seen throughout much of the democratic world actually facilitates or indeed hinders the resolution of moral-ethical dilemmas in society.

Rawls argues: 'Justice is the first virtue of social institutions... laws and institutions no matter how efficient and well-arranged must be reformed or abolished if they are unjust'. Potentially my study will advance greater public discussion on this topic in a formal capacity. For example, the then Tánaiste Eamon Gilmore, during Dáil proceedings, highlighted the need for a specialist report to be conducted by an 'expert group' to engage with the 
right-to-die topic, submitting that 'members of the House should deal with the issue as legislators'. It is my plan to eventually make a considerable contribution to these proposed national policy decisions and offer my work either wholly or as a template for this possible engagement of reformation. My goal is to synthesise Irish research on this topic with our European counterparts and become the pioneer of sociological and philosophical research on competing justice frames on the right-to-die in Ireland. Being a leading researcher within this field promotes the importance of this study and its impact.

\section{Conclusion}

It is only through the disentangling and clearer reconstruction of the considerations contained within this subject that a more transparent framework for resolution can be found. Much evidence suggests more in-depth research is drastically required to classify this highly divisive topic as it has moved through various degrees of public debate recently from the public arena, the media, and the Dáil to the High Court and the Supreme Court. My research will offer clarity to this often cluttered debate. Moreover, this cutting-edge study not only breaks new ground in a sociological and philosophical research sense, it will also provide a richly deserved platform of understanding towards those affected by this issue, whom are typically marginalised in society, to occur. Although Marie Fleming's method of dying was against her wishes after she was denied that 'right' having opted to enter formal judicial proceedings, she passed away surrounded by her family and partner Tom Curran. Bernadette Forde took the law into her own hands to relieve herself of her suffering. Feeling 'angry and frustrated' she died alone. Not because she did not have loving compassionate family and carers in her life. She was alone because the law required that she be alone. There is something fundamentally wrong in society when people are forced to such extreme measures. Because none of us know the circumstances or nature of our impending deaths, this issue has the potential to affect each and every one of us in the future. This study hopes to facilitate a more harmonious and ethically compassionate approach to this dilemma.

James Keogh is a PhD candidate from the Department of Sociology and Philosophy working under the supervision of Dr Tracey Skillington and Dr Cara Nine. The author would like to express his sincere thanks to those who have aided his research thus far, especially his parents. Also, a special thanks to Alison for her constant love, support, and understanding. 